\title{
Potentially Inappropriate Prescriptions to Older Patients in Emergency Departments in South Korea: A Retrospective Study
}

This article was published in the following Dove Press journal: Therapeutics and Clinical Risk Management

\author{
Kyungim $\operatorname{Kim} \mathbb{D}^{1,2, *}$ \\ Jinyoung Jung $\mathbb{B D}^{2, *}$ \\ Haesook $\mathrm{Kim}^{3}$ \\ Jung Tae $\mathrm{Kim}^{4}$ \\ Jung $\mathrm{MiOh} \mathbb{D}^{5}$ \\ Hyunah $\mathrm{Kim}^{6,7}$
}

'College of Pharmacy, Korea University, Sejong, Republic of Korea; ${ }^{2}$ Institute of Pharmaceutical Science, Korea University, Sejong, Republic of Korea; ${ }^{3}$ Department of Pharmacy, Gang Neung Asan Hospital, Gangneung, Republic of Korea;

${ }^{4}$ Department of Pharmacy, Kyung Hee University Hospital at Gangdong, Seoul, Republic of Korea; ${ }^{5}$ College of Pharmacy and Research Institute of Pharmaceutical Sciences, Seoul National University, Seoul, Republic of Korea; ${ }^{6}$ College of Pharmacy, Sookmyung Women's University, Seoul, Republic of Korea; ${ }^{7}$ Drug Information Research Institute, College of Pharmacy, Sookmyung Women's University, Seoul, Republic of Korea

*These authors contributed equally to this work
Correspondence: Hyunah Kim College of Pharmacy, Sookmyung Women's University, Cheongpa-ro 47-gil 100, Yongsan-gu, Seoul, 04310, Republic of Korea

Tel +82-2-2077-7961

Email hyunah@sookmyung.ac.kr
Purpose: The purpose of this study was to evaluate the incidence of the administration of potentially inappropriate medications (PIMs) and the potential drug-drug interactions (pDDIs) in older patients in emergency departments (EDs) over a 12-month period and to identify the factors associated with the administration of PIMs.

Patients and Methods: This retrospective study was conducted using the electronic medical records from two university-affiliated teaching hospitals in South Korea. ED visit cases of patients aged 65 and older from January 1, 2013, to December 31, 2013, were included in the analysis. Among the medications administered in ED, PIMs or pDDIs were identified using a drug utilization review program available in Korea.

Results: During the study period, a total of 13,002 ED visit cases were reported from 10,686 patients. The proportion of ED visit cases with any PIM was $79.2 \%$ and the average number of PIMs was 2.7 (range, 1-17). The most commonly administered PIMs that were contraindicated or should have been used with caution were ketorolac (41.3\%) and metoclopramide $(10.3 \%)$, respectively. Multivariate regression analysis indicated that female patients $(p=0.012)$, patients with more than six drugs in the ED $(p<0.001)$, and visits longer than 300 minutes $(p=0.026)$ were significantly associated with PIM administration in the ED. Potential DDIs between the medications administered in EDs were observed in $20.5 \%$ of total visit cases, with ketorolac being the most frequently reported drug in contraindicated drug combinations.

Conclusion: This study demonstrated a high incidence of the administration of PIMs and medications with pDDIs in older patients in EDs and revealed the characteristics that are significantly associated with an increased risk of PIM administration. Healthcare providers in EDs should consider the risk of administering PIMs or medications with pDDIs, especially when treating older patients.

Keywords: emergency department, older adults, potentially inappropriate medications, drug-drug interactions, drug utilization review

\section{Introduction}

The emergency department (ED), the place to institute the immediate medical care of patients with acute illness or injury, is at the intersection between inpatient and outpatient care and can have a meaningful impact on patients' conditions. ${ }^{1-3}$ However, EDs are of increasing concern as high-risk environments for potentially inappropriate medication (PIM) use and adverse drug events. Certain characteristics of EDs such as patients overcrowding, a lack of skilled workers, and the high turnover of admitted or discharged patients can hinder the provision of optimal emergency care services. 4,5 
As the aging of society accelerates, the older adults aged 65 and over account for the largest and fastest growing age group of patients visiting EDs. The proportion of visits by older patients to EDs was reported as $24 \%$ in Italy, $31 \%$ in Spain, and $22 \%$ in the United States. ${ }^{6-8}$ In Korea, the rate of admission to EDs by older patients has risen from $15.2 \%$ in 2005 to $23.9 \%$ in $2016 .{ }^{9}$ Because older adults are sensitive to medicines, the administration of PIMs can lead to adverse drug events, which can have serious medical and safety consequences especially for older adults. ${ }^{10}$ Moreover, the side effects of these drugs can cause problems long after administration, as many drugs have a longer half-life in the older adults than in younger age people due to changes in pharmacokinetic parameters with aging. ${ }^{11}$ Some previous studies have shown that exposure to PIMs or potential drug-drug interactions (pDDIs) was associated with an increased risk of re-hospitalization and unplanned hospitalization in the older adults. ${ }^{12-14}$ Therefore, the need for and importance of appropriate medication use for the older adults visiting EDs should be particularly emphasized.

Potentially inappropriate prescriptions have been well studied in both nursing home and community-dwelling older adult settings. However, less is known about it for older patients visiting EDs. Therefore, the purposes of this study were to determine the incidence and characteristics of PIM use and pDDIs and to identify the factors related to PIM administration, with a particular focus on the older patients visiting EDs.

\section{Patients and Methods}

\section{Study Population and Data Collection}

This retrospective study was conducted from January to December 2013 at two university-affiliated teaching hospitals in South Korea. Of the patients who visited the EDs in 2013, those aged 65 years and older were included in this study. Patient demographic information and visit characteristics to the EDs were collected from each hospital's electronic medical records (EMRs). These included the patient's age, sex, diagnosis in the ED (ICD-10 code), the medications administered in the ED (brand name, ingredient, ATC code), their length of ED stay, and condition after discharge from the ED. Information about the medications that were administered in the ED was prepared by checking the actual dosing time on the EMR, not simply the physician's order list. To protect the privacy of the patients involved, all data were encoded and protected.
This study was conducted with the approval of the Institutional Review Board of Kyung Hee University Hospital at Gangdong (IRB No. 2014-08-003) and Gangneung Asan Hospital (IRB No. 2014-046) in accordance with the Declaration of Helsinki. The requirement for informed consent was waived due to the retrospective nature of the study.

\section{Evaluation of PIMs and pDDls}

Potentially inappropriate medications and pDDIs in the older adults were identified using a commercially available drug utilization review (DUR) database program in Korea (DIKPlus, FirstDIS Ltd, Seoul, Korea). This DUR program provides information on drug-drug interactions, contraindications, and precautions for special population groups such as older adults, children, as well as pregnant and breastfeeding women. For PIMs and pDDIs in older adults, the database was developed by reviewing the Beers Criteria of the American Geriatric Society and the list of drugs to be used with caution in older patients which is provided by the Korea Food and Drug Administration. In addition, product package inserts, US Hospital Preparation Service (AHFS) medication information, Merck manual, US Food and Drug Administration MedWatch and Health Canada were reviewed. Based on these databases, this DUR program classified PIMs in older patients into two groups according to their severity: contraindications (severity level II) and precautions (severity level I). Potential DDIs were classified into three groups: contraindications (severity level III), severe interactions requiring treatment modification (severity level II), and moderate interactions requiring careful monitoring (severity level I).

In this study, medications that are inappropriate only at a specific dose, duration of administration, or comorbid conditions were not included because this information could not be identified. Therefore, the PIMs and pDDIs considered in this study were those listed on the references regardless of diagnosis or condition.

\section{Statistical Analysis}

All the statistical analysis was performed on an ED visit, rather than patient case basis. Categorical variables were summarized as values and percentages, and continuous variables were presented as medians and ranges. To understand the characteristics of the medications administered in ED, a descriptive analysis was performed. Multivariate logistic regression analysis was used to identify the 
predictors of PIM administration. For each ED visit case, the independent variables in the regression model included patient characteristics, such as sex and age, and visit characteristics, such as the number of medications administered and the length of stay. The dependent variable was the PIM occurrence. Two-sided P-values less than 0.05 were considered as statistically significant. All analyses were performed using SAS.

\section{Results}

\section{Characteristics of the ED Visit Cases}

Table 1 shows the overall characteristics of the ED visit cases. During the study period, a total of 13,002 ED visit cases by 10,686 patients were reported. Some patients had visited the ED more than once (range, 1-18). The median age for the ED visit cases was 74 years (range, 65-104 years). Out of the total cases, 6094 (46.9\%) were male and 6908 (53.1\%) were female. The median number of diagnoses and medications administered in EDs was 1 (range, 1-3) and 5 (range, 1-55), respectively. The five most common diseases diagnosed in EDs were "Cerebral infarction, unspecified" (545, 4.2\%), "Dizziness and giddiness" (463, 3.6\%), "Gastroenteritis and colitis of unspecified origin" (336, 2.6\%), "Pneumonia, unspecified" $(318,2.5 \%)$ and "Unspecified abdominal pain" (204, 1.6\%) (Supplementary Table S1). The average length of ED stay was 196 minutes (range, 1-2208 minutes). After the ED visit, there were 6698 cases of hospitalizations $(51.5 \%)$ and 6154 cases of discharge $(47.4 \%)$.

\section{Analysis of PIM Use}

Of the total ED visit cases, 10,291 (79.2\%) contained at least one PIM in their ED administered medication. Between the visit cases with PIMs and those without them, there were significant differences in sex, age, number of medications administered, length of ED stay, and post-discharge status (Table 1).

Of the visit cases with at least one PIM, the average number of PIMs administered in ED was 2.7 (range, 1-17). A total of 7355 (71.5\%) visits received $\geq 2$ PIMs, and $4584(44.5 \%)$ visits received $\geq 3$ PIMs. There were $303(2.9 \%)$ visit cases with only PIMs of severity II (contraindications) and $8125(79.0 \%)$ visit cases with only PIMs of severity I (precautions). Moreover, 1863 (18.1\%) visit cases had PIMs of both severities I and II (Table 2).
In this study, 22 and 219 PIMs corresponding to severity II and I were administered 2615 and 25,343 times, respectively. The five most commonly administered medications are listed in Table 3. The administered PIMs corresponding to severity II in order of the most common were ketorolac $(1081,41.3 \%)$, chlorpheniramine (615, $23.5 \%$ ), midazolam $(236,9.0 \%)$, diazepam (197, 7.5\%), and triprolidine/pseudoephedrine (114, 4.4\%). These five medications accounted for $85.8 \%$ of all the severity level II PIMs. Other medications, including methocarbamol, nifedipine (short-acting), amitriptyline, bisacodyl, and piroxicam accounted for a smaller percentage of the total PIMs (Supplementary Table S2). When analyzed in the same way, the administered PIMs corresponding to severity level $\mathrm{I}$ in order of the most common were metoclopramide (2606, 10.3\%), famotidine (2312, 9.1\%), tramadol (1822, 7.2\%), acetaminophen (1269, 5.0\%) and nitroglycerine $(981,3.9 \%)$. These five medications accounted for $35.5 \%$ of all the severity level I PIMs. Other medications such as aspirin, heparin, ranitidine, furosemide, fluoroquinolones (ciprofloxacin, levofloxacin), and opioids (pethidine, fentanyl, morphine) followed (Supplementary Table S3).

The results of the multivariate logistic regression analysis are noted in Table 4. They indicated that female patients were more associated with increased risk of PIM administration than male patients, and this difference was significant [OR $1.13(1.03-1.23), \mathrm{p}=0.012$ ]. The visits associated with administered medications numbering six to seven and eight or more had higher risks of PIM administration when compared to the control [OR 16.42 (12.85-21.00), $\mathrm{p}<0.001$; OR 36.23 (26.21-50.09), $\mathrm{p}<0.001$; respectively] (Figure 1). It was found that the length of ED stay of more than 300 minutes had a significantly higher risk of PIM administration than the control [1.15 (1.02-1.29), $\mathrm{p}=0.026$ ]. However, those aged between 75 and 84 were significantly associated with a decreasing odds ratio of PIM administration [OR 0.88 (0.79-0.97), $\mathrm{p}=0.008$ ].

\section{Analysis of pDDIs}

During the study period, pDDI between the medications administered in ED was observed in 2668 visit cases (20.5\% of the total visit cases). Potential DDIs corresponding to severity III (contraindications), severity II (severe interactions), and severity I (moderate interactions) were reported from 161 visits (1.2\%), 607 visits (4.7\%), and 1900 visits (14.6\%), respectively. The five most commonly administered medication combinations with respect to the 
Table I Characteristics of the ED Visit Cases

\begin{tabular}{|c|c|c|c|c|}
\hline $\begin{array}{l}\text { Characteristics, } \\
\text { No. (\%) }\end{array}$ & $\begin{array}{l}\text { Total } \\
\text { Visit }\end{array}$ & $\begin{array}{l}\text { Visit } \\
\text { with } \\
\text { PIMs }^{a}\end{array}$ & $\begin{array}{l}\text { Visit } \\
\text { without } \\
\text { PIM }^{\mathrm{a}}\end{array}$ & P-value \\
\hline No. of visits & $\begin{array}{l}13,002 \\
(100.0)\end{array}$ & $\begin{array}{l}|0,29| \\
(79.1)\end{array}$ & $\begin{array}{l}2711 \\
(20.9)\end{array}$ & - \\
\hline \multicolumn{5}{|l|}{ Sex } \\
\hline $\begin{array}{l}\text { Male } \\
\text { Female }\end{array}$ & $\begin{array}{l}6094 \\
(46.9) \\
6908 \\
(53.1)\end{array}$ & $\begin{array}{l}4776 \\
(46.4) \\
5515 \\
(53.6)\end{array}$ & $\begin{array}{l}1318 \\
(48.6) \\
1393 \\
(51.4)\end{array}$ & 0.040 \\
\hline \multicolumn{5}{|l|}{ Age (year) } \\
\hline $\begin{array}{l}65-74 \\
75-84 \\
\geq 85\end{array}$ & $\begin{array}{l}6569 \\
(50.5) \\
4891 \\
(37.6) \\
1542 \\
(11.9)\end{array}$ & $\begin{array}{l}5274 \\
(51.2) \\
3816 \\
(37.1) \\
1201 \\
(I 1.7)\end{array}$ & $\begin{array}{l}1295 \\
(47.8) \\
1075 \\
(39.7) \\
341(12.6)\end{array}$ & 0.005 \\
\hline \multicolumn{5}{|c|}{ No. of diagnoses in ED } \\
\hline$\geq 2$ & $\begin{array}{l}12,484 \\
(96.0) \\
518 \\
(4.0)\end{array}$ & $\begin{array}{l}9888 \\
(96.1) \\
403(3.9)\end{array}$ & $\begin{array}{l}2596 \\
(95.8) \\
115(4.2)\end{array}$ & 0.440 \\
\hline \multicolumn{5}{|c|}{ No. of medications administered in ED } \\
\hline $\begin{array}{l}I-5 \\
6-7 \\
\geq 8\end{array}$ & $\begin{array}{l}7827 \\
(60.2) \\
2324 \\
(17.9) \\
2851 \\
(21.9)\end{array}$ & $\begin{array}{l}5222 \\
(50.7) \\
2256 \\
(21.9) \\
2813 \\
(27.3)\end{array}$ & $\begin{array}{l}2605 \\
(96.1) \\
68(2.5) \\
38(1.4)\end{array}$ & $<0.001$ \\
\hline \multicolumn{5}{|c|}{ Length of ED stay (minutes) } \\
\hline $\begin{array}{l}1-196 \\
197-299 \\
\geq 300\end{array}$ & $\begin{array}{l}6533 \\
(50.2) \\
3235 \\
(24.9) \\
3234 \\
(24.9)\end{array}$ & $\begin{array}{l}5065 \\
(49.2) \\
2528 \\
(24.6) \\
2698 \\
(26.2)\end{array}$ & $\begin{array}{l}1468 \\
(54.1) \\
707(26.1) \\
536(19.8)\end{array}$ & $<0.001$ \\
\hline \multicolumn{5}{|c|}{ Condition after ED visit } \\
\hline Hospitalization & $\begin{array}{l}6698 \\
(51.5)\end{array}$ & $\begin{array}{l}5439 \\
(52.9)\end{array}$ & $\begin{array}{l}1259 \\
(46.4)\end{array}$ & $<0.001$ \\
\hline Home & $\begin{array}{l}6154 \\
(47.4)\end{array}$ & $\begin{array}{l}4714 \\
(45.8)\end{array}$ & $\begin{array}{l}1440 \\
(53.1)\end{array}$ & \\
\hline Death & $\begin{array}{l}12 \mid \\
(0.9)\end{array}$ & $116(1.1)$ & $5(0.2)$ & \\
\hline Not assessed & $29(0.2)$ & $22(0.2)$ & $7(0.3)$ & \\
\hline
\end{tabular}

Note: ${ }^{\text {aEach }}$ percentage was calculated out of the total number of corresponding visits.

Abbreviations: ED, emergency department; PIM, potentially inappropriate medication.
Table 2 Incidence of Visit Cases with PIM

\begin{tabular}{|l|l|l|}
\hline $\begin{array}{l}\text { Severity } \\
\text { Level }\end{array}$ & $\begin{array}{l}\text { No. of Visit with } \\
\text { PIMs (\%) }\end{array}$ & $\begin{array}{l}\text { No. of PIMs Administered, } \\
\text { Average (Range) }\end{array}$ \\
\hline II only & $303(2.9)$ & $1.2(1-4)$ \\
I only & $8125(79.0)$ & $2.5(1-16)$ \\
II and I & $1863(18.1)$ & $4.2(2-17)$ \\
\hline
\end{tabular}

Abbreviation: PIM, potentially inappropriate medication.

Table 3 Top 5 Ranked PIMs

\begin{tabular}{|l|l|l|}
\hline Severity Level & Medication & n (\%) \\
\hline Severity II: & Ketorolac & $1081(41.3)$ \\
Contraindications & Chlorpheniramine & $615(23.5)$ \\
& Midazolam & $236(9.0)$ \\
& Diazepam & $197(7.5)$ \\
& Triprolidine/ & $114(4.4)$ \\
& pseudoephedrine & \\
\hline \multirow{2}{*}{ Severity I: } & Metoclopramide & $2606(10.3)$ \\
& Famotidine & $2312(9.1)$ \\
& Tramadol & $1822(7.2)$ \\
& Acetaminophen & $1269(5.0)$ \\
& Nitroglycerine & $981(3.9)$ \\
\hline
\end{tabular}

Note: ${ }^{2}$ Each percentage was calculated out of the total number of administration at each severity level.

Abbreviation: PIM, potentially inappropriate medication.

three severity levels are listed in Table 5. The medication combinations corresponding to severity III were in the order of the most common ketorolac-aceclofenac $(61,37.9 \%)$, ketorolac-celecoxib (32, 19.9\%), ketorolac-ibuprofen (20, $12.4 \%$ ), levofloxacin-amiodarone (12, 7.5\%), and esomeprazole-clopidogrel $(10,6.2 \%)$. These five combinations accounted for $83.9 \%$ of all the severity level III pDDIs (Supplementary Table S4). When analyzed in the same way, the medication combinations corresponding to severity II were in the order of the most common aspirin-heparin (424, 69.9\%), levofloxacin-human insulin (31, 5.1\%), ciprofloxacin-human insulin (17, 2.8\%), amiodarone-diltiazem (13, 2.1\%), and amitriptyline-acetaminophen/tramadol (13, $2.1 \%$ ), and those corresponding to severity I were in the order of the most common aspirin-clopidogrel (510, $26.8 \%$ ), heparin-clopidogrel $(346,18.2 \%)$, atorvastatinclopidogrel (181, 9.5\%), furosemide-candesartan (73, $3.8 \%)$, and levofloxacin-budesonide (47, 2.5\%) (Supplementary Table S5 and S6).

\section{Discussion}

To the best of our knowledge, this is the first DUR study to focus on the appropriateness of the drugs administered in 
Table 4 Crude and Adjusted Odds Ratios for Factors Influencing PIM Administration

\begin{tabular}{|c|c|c|c|c|}
\hline \multirow[t]{2}{*}{ Characteristics } & \multicolumn{2}{|l|}{ Crude Model } & \multicolumn{2}{|l|}{ Adjusted Model } \\
\hline & OR $(95 \% \mathrm{CI})$ & P-value & OR (95\% Cl) & P-value \\
\hline \multicolumn{5}{|l|}{ Sex } \\
\hline Male & I.00 (Reference) & & I.00 (Reference) & \\
\hline Female & $1.09(1.004-1.19)$ & 0.041 & $1.13(1.03-1.23)$ & 0.012 \\
\hline \multicolumn{5}{|l|}{ Age (years) } \\
\hline $65-74$ & I.00 (Reference) & & I.00 (Reference) & \\
\hline $75-84$ & $0.87(0.80-0.96)$ & 0.003 & $0.88(0.79-0.97)$ & 0.008 \\
\hline$\geq 85$ & $0.87(0.76-0.99)$ & 0.035 & $0.87(0.75-1.002)$ & 0.053 \\
\hline$p$-for trend & & 0.004 & & 0.007 \\
\hline \multicolumn{5}{|c|}{ No. of medications administered in ED } \\
\hline $1-5$ & I.00 (Reference) & & I.00 (Reference) & \\
\hline $6-7$ & $16.55(12.94-21.16)$ & $<0.001$ & $16.42(\mid 2.85-21.00)$ & $<0.001$ \\
\hline$\geq 8$ & $36.9(26.7 I-50.99)$ & $<0.001$ & $36.23(26.21-50.09)$ & $<0.001$ \\
\hline$p$-for trend & & $<0.001$ & & $<0.001$ \\
\hline \multicolumn{5}{|c|}{ Length of ED stay (minutes) } \\
\hline $1-196$ & I.00 (Reference) & & I.00 (Reference) & \\
\hline $197-299$ & $1.04(0.94-1.15)$ & 0.491 & $1.01(0.90-1.12)$ & 0.903 \\
\hline$\geq 300$ & $1.46(1.31-1.63)$ & $<0.001$ & $1.15(1.02-1.29)$ & 0.026 \\
\hline$p$-for trend & & $<0.001$ & & 0.029 \\
\hline
\end{tabular}

Abbreviations: ED, emergency department; PIM, potentially inappropriate medication.

EDs to older Korean patients. There have been a few studies that have evaluated PIMs in older patients in Korea, but all of them were conducted in outpatient settings or long-term care facilities. ${ }^{15-19}$ This study observed that, of the total ED visit cases by older patients, $79.2 \%$ and $20.5 \%$ involved at least one PIM and pDDI in the medications administered in ED, respectively. The independent variables of sex, the number of medications administered in ED, and the length of ED stay were significantly associated with PIM administration.

The overall incidence of PIM administration detected in this study (79.2\%) was higher than previous large-scale studies conducted in Western and Asian countries using ED data $(15 \%$ to $53 \%) .{ }^{10,20-23}$ Although Harrison et al reported that $76 \%$ of study patients received at least one prescription with PIM according to Beers criteria, the total sample size of their study was small $(n=400) .{ }^{24}$ The high incidence of the administration of PIMs in this study could be principally explained by the DUR program used in this study, which contains more country-specific medications than the Beers Criteria primarily used in the previous studies. The Beers Criteria has been used to warn of PIM in older patients for a long time, but it is difficult to apply equally to all countries since the available medications and prescription preferences vary by country. In support of this view, Chang et al confirmed that large differences of PIM incidence among older patients in EDs in their study using the Taiwan National Health Insurance Research Database corresponded to differences between country-specific and country non-specific PIM criteria, and they emphasized the importance of establishing country-specific PIM criteria as references for clinical practice in EDs. ${ }^{22}$

In this study, the frequently administered PIMs corresponding to severity II (contraindication) were usually symptom relief drugs including ketorolac, chlorpheniramine, benzodiazepines such as midazolam and diazepam, and triprolidine/pseudoephedrine. These results are similar to previous studies. ${ }^{10,21-23}$ Ketorolac is known to cause gastrointestinal toxicity, and chlorpheniramine may cause sedation and urinary retention due to its anticholinergic activity in the older adults. Benzodiazepines have a sedative effect, and there is a risk of hypotension or paradoxical reactions in the older adults. The current study found that each of the five most frequently 


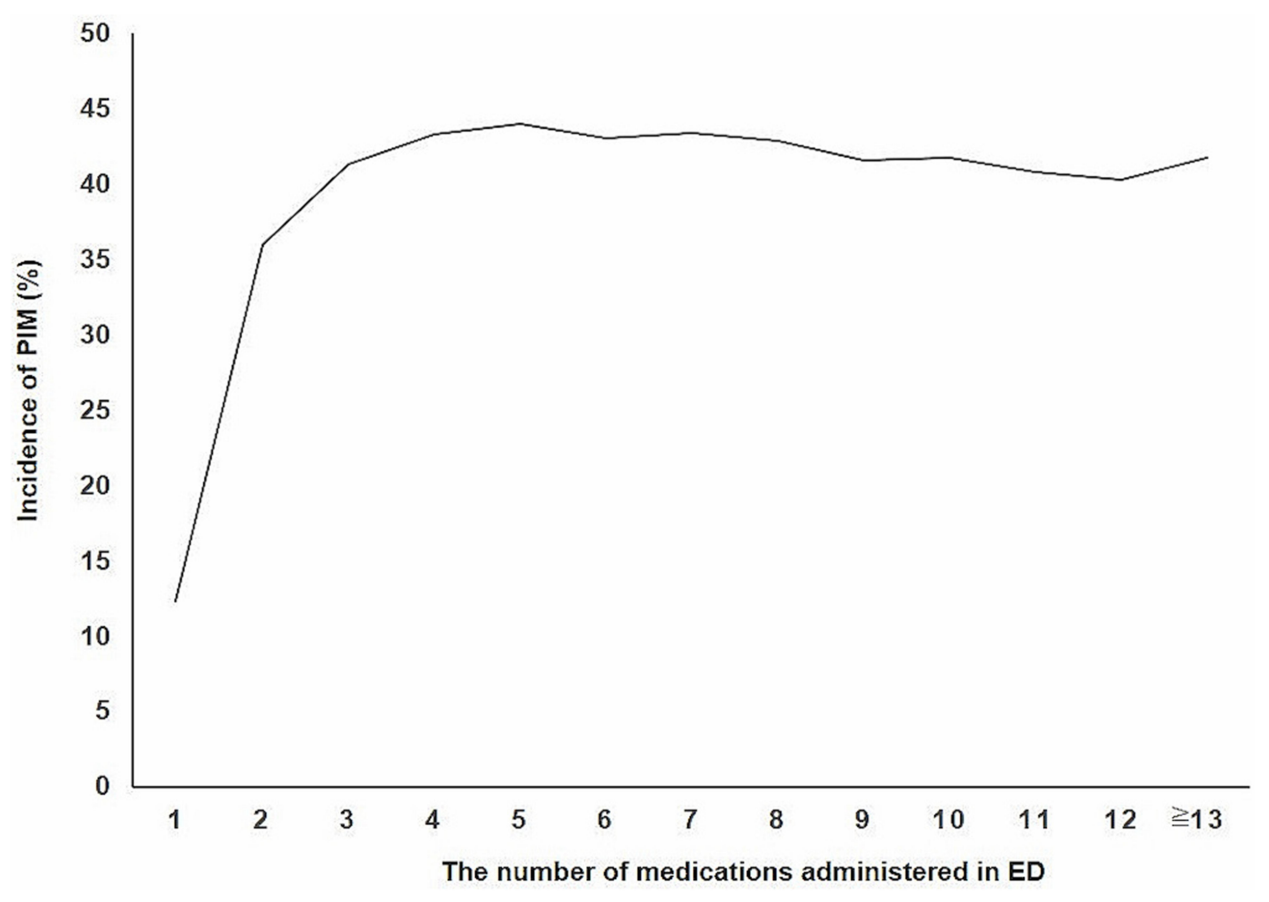

Figure I Relationship between PIM incidence and the number of medications administered in ED. Abbreviations: PIM, potentially inappropriate medication; ED, emergency department.

administered medications of severity II and I accounted for $85.8 \%$ and $35.5 \%$ of their total PIMs, respectively. Therefore, it would be very beneficial to encourage ED doctors to consider the risk-benefit ratio before prescribing particularly these drugs, to older patients in ED.

The multivariate logistic regression analysis in this study identified female patients, the number of medications administered in ED, and the length of ED stay as factors significantly increasing the risk of PIM administration to older patients visiting EDs, and this is consistent with previous studies. ${ }^{10,21}$ In this regard, previous studies have explained that females are generally more susceptible to inappropriate prescriptions because they are generally at a higher risk of developing several chronic conditions than males. $^{25,26}$ In addition, female patients are known to use more sleep-inducing drugs, antidepressants, and analgesics than males, because of their higher prevalence of anxiety disorders, depression, and sleep disorders. ${ }^{27}$ Interestingly, the incidence of PIM administration was reported to be lower in older patients aged between 75 and 84 years than in the control group (aged between 65 and 74). This result could be explained by ED doctors tending to assess the appropriateness of medications more carefully prior to prescribing to older patients. Further research is needed to clarify the reasons for this observation.
Potential DDIs between the medications administered in ED were also evaluated in this study. The pDDI incidence was $20.5 \%$ of total visit cases, and the most frequently reported contraindicated drug combinations were ketorolac and other nonsteroidal anti-inflammatory drugs (NSAIDs). Ketorolac, also the most frequently administered PIM in the current study, can cause serious gastrointestinal problems such as bleeding or peptic ulcers. Its gastrointestinal toxicity is known to be five times stronger than any other NSAID. ${ }^{28}$ Moreover, ketorolac combinations with other NSAIDs may enhance the risk of gastrointestinal adverse effects.

The prescriptions given in ED are short-term and onetime doses, and the ED situation is generally more critically urgent than that of any other station. Nevertheless, PIMs or pDDIs should be considered carefully since in older patients they can cause severe adverse effects, even in a single dose. Strategies to promote such caution have been applied over the past decade, such as the development of guidelines for the management of medication of the older patients in EDs or software that automatically generates electronic alerts for PIMs or pDDIs in the prescription process. ${ }^{3}$ However, their effectiveness at ensuring safe medication prescription and administration has had limitations. For example, it was reported that a high percentage $(35-96 \%)$ of automatically generated 
Table 5 Top 5 Ranked pDDls

\begin{tabular}{|c|c|c|}
\hline Severity Level & Drug-Drug Interaction & n (\%) $)^{a}$ \\
\hline $\begin{array}{l}\text { Severity III: } \\
\text { Contraindications }\end{array}$ & $\begin{array}{l}\text { Ketorolac-aceclofenac } \\
\text { Ketorolac-celecoxib } \\
\text { Ketorolac-ibuprofen } \\
\text { Levofloxacin-amiodarone } \\
\text { Esomeprazole-clopidogrel }\end{array}$ & $\begin{array}{l}61 \\
(37.9) \\
32 \\
(19.9) \\
20 \\
(12.4) \\
12 \\
(7.5) \\
10 \\
(6.2)\end{array}$ \\
\hline $\begin{array}{l}\text { Severity II: Severe } \\
\text { interactions }\end{array}$ & $\begin{array}{l}\text { Aspirin-heparin } \\
\text { Levofloxacin-human } \\
\text { insulin } \\
\text { Ciprofloxacin-human } \\
\text { insulin } \\
\text { Amiodarone-diltiazem } \\
\text { Amitriptyline- } \\
\text { acetaminophen/tramadol }\end{array}$ & $\begin{array}{l}424 \\
(69.9) \\
31 \\
(5.1) \\
17 \\
(2.8) \\
13 \\
(2.1) \\
13 \\
(2.1)\end{array}$ \\
\hline $\begin{array}{l}\text { Severity I: Moderate } \\
\text { interactions }\end{array}$ & $\begin{array}{l}\text { Aspirin-clopidogrel, } \\
\text { Heparin-clopidogrel, } \\
\text { Atorvastatin-clopidogrel } \\
\text { Furosemide-candesartan } \\
\text { Levofloxacin-budesonide }\end{array}$ & $\begin{array}{l}510 \\
(26.8) \\
346 \\
(18.2) \\
181 \\
(9.5) \\
73 \\
(3.8) \\
47 \\
(2.5)\end{array}$ \\
\hline
\end{tabular}

Note: ${ }^{a}$ Each percentage was calculated out of the total number of pDDls at each severity level.

Abbreviation: pDDIs, potential drug-drug interactions.

electronic alerts were often ignored by doctors because of inadequate alerts for a specific clinical situation or the intended prescription. ${ }^{29}$ To improve the situation, a more comprehensive review of prescription drugs based on clinical relevance and a better understanding of the unique medical environment of each country is needed. For this, doctor-pharmacist collaboration in ED may be the answer. Recent studies found that pharmacist-assisted medication reconciliation and integration system or academic detailing of physician residents provided by physician-pharmacist pairs contributed to reduce PIM prescription to older patients in ED practices. ${ }^{30,31}$

The strength of the current study was that it was able to accurately and completely collect patient-specific drug administration records and other details during ED visits using the EMR data collected from two large universityaffiliated teaching hospitals. In addition, the PIM criteria used in this study contained more country-specific and substantial data than Beers Criteria which is commonly used criteria in Western countries. This allowed other medications that were not identified as potentially harmful by Beers Criteria (for example, opioid analgesics) to be reviewed in this study. Despite these strengths, this study has some limitations which should be interpreted carefully. First, since this study was conducted with ED data from two hospitals, it is difficult to generalize the study results in different environments. Second, although this study evaluated the incidence of PIM administration or pDDI in EDs, it did not evaluate the actual incidence of associated adverse drug reactions. Finally, this study was conducted in 2013. Nevertheless, we believe that the results of this study may help in promoting safe drug use in older patients in EDs, since PIMs and pDDIs are still recognized as important issues, especially in older patients.

\section{Conclusion}

This study demonstrated that older Korean patients were highly exposed to PIMs and medications with pDDIs in the ED. Therefore, healthcare providers in the EDs should carefully consider the risk of administering PMIs or medications with pDDIs, especially when treating female patients, patients who have been prescribed many medications in the $\mathrm{ED}$, and patients who have stayed in the ED for a long time.

\section{Acknowledgments}

The authors acknowledge the efforts of Department of Pharmacy of Gang Neung Asan Hospital and Kyung Hee University Hospital at Gangdong for collecting clinical data and providing administrative supports.

\section{Funding}

This study was supported by the National Research Foundation, Korea (NRF-2020R1F1A1069257) and the Ministry of Health \& Welfare (MOHW, Korea).

\section{Disclosure}

The authors declare no potential conflicts of interests.

\section{References}

1. Carpenter CR, Platts-Mills TF. Evolving prehospital, emergency department, and "inpatient" management models for geriatric emergencies. Clin Geriatr Med. 2013;29(1):31-47. doi:10.1016/j. cger.2012.09.003 
2. Hwang U, Morrison RS. The geriatric emergency department. $J$ Am Geriatr Soc. 2007;55(11):1873-1876. doi:10.1111/j.15325415.2007.01400.x

3. American GS, Geriatric EDGTF, Physicians A, Association EN. Geriatric emergency department guidelines. Ann Emerg Med. 2014;63(5):e7.

4. Derlet RW, Richards JR. Overcrowding in the nation's emergency departments: complex causes and disturbing effects. Ann Emerg Med. 2000;35(1):63-68. doi:10.1016/S0196-0644(00)70105-3

5. Rondeau KV, Francescutti LH, Zanardelli JJ. Emergency department overcrowding: the impact of resource scarcity on physician job satisfaction/practitioner application. J Healthc Manag. 2005;50(5):327. doi:10.1097/00115514-200509000-00009

6. Bermúdez Menéndez de la Granda M, Guzmán Gutiérrez G, Fernández Fernández M, Solano Jaurrieta JJ. Impact of the elderly patient in the emergency department. Rev Esp Geriatr Gerontol. 2017;53(3):145-148. doi:10.1016/j.regg.2017.08.003

7. Salvi F, Mattioli A, Giannini E, et al. Pattern of use and presenting complaints of older patients visiting an emergency department in Italy. Aging Clin Exp Res. 2013;25(5):583-590. doi:10.1007/ s40520-013-0112-z

8. National Center for Health Statistics (US). Health, United States, 2018. Hyattsville, MD: National Center for Health Statistics (US); 2019. Available from: https://www.ncbi.nlm.nih.gov/books/ NBK551095/.

9. Lim J, Lee J. Factors associated with mortality of older adults hospitalized via emergency departments in Korea. Korean J Adult Nurs. 2020;32(3):273-282. doi:10.7475/kjan.2020.32.3.273

10. Chen YC, Hwang SJ, Lai HY, et al. Potentially inappropriate medication for emergency department visits by elderly patients in Taiwan. Pharmacoepidemiol Drug Saf. 2009;18(1):53-61. doi:10.1002/pds.1684

11. Mangoni AA, Jackson SH. Age-related changes in pharmacokinetics and pharmacodynamics: basic principles and practical applications. Br J Clin Pharmacol. 2003;57(1):6-14. doi:10.1046/j.13652125.2003.02007.x

12. Price SD, Holman CDAJ, Sanfilippo FM, Emery JD. Association between potentially inappropriate medications from the Beers criteria and the risk of unplanned hospitalization in elderly patients. Ann Pharmacother. 2014;48(1):6-16. doi:10.1177/1060028013504904

13. Pedrós C, Formiga F, Corbella X, Arnau JM. Adverse drug reactions leading to urgent hospital admission in an elderly population: prevalence and main features. Eur J Clin Pharmacol. 2016;72 (2):219-226. doi:10.1007/s00228-015-1974-0

14. Wang P, Wang Q, Li F, Bian M, Yang K. Relationship between potentially inappropriate medications and the risk of hospital readmission and death in hospitalized older patients. Clin Interv Aging. 2019;14:1871. doi:10.2147/CIA.S218849

15. Lim Y-J, Kim H-Y, Choi J, et al. Potentially inappropriate medications by beers criteria in older outpatients: prevalence and risk factors. Korean J Fam Med. 2016;37(6):329. doi:10.4082/ kjfm.2016.37.6.329

16. Hwang H-J, Kim S-H, Lee KS. Potentially inappropriate medications in the elderly in Korean long-term care facilities. Drugs-Real World Outcomes. 2015;2(4):355-361. doi:10.1007/s40801-015-0046-1

17. Hong S, Lee JH, Chun EK, et al. Polypharmacy, inappropriate medication use, and drug interactions in older Korean patients with cancer receiving first-line palliative chemotherapy. Oncologist. 2020;25(3):e502. doi:10.1634/theoncologist.2019-0085

18. Kim DS, Jeon HL, Park J, Bae S. Factors associated with potentially inappropriate medication use in elderly Koreans in an outpatient setting: a population-based study. J Am Geriatr Soc. 2016;64(9): e21-23. doi:10.1111/jgs.14267
19. Jeon HL, Park J, Han E, Kim DS. Potentially inappropriate medication and hospitalization/emergency department visits among the elderly in Korea. Int $J$ Qual Health Care. 2018;30(1):50-56. doi:10.1093/intqhe/mzx171

20. Brown JD, Hutchison LC, Li C, Painter JT, Martin BC. Predictive validity of the Beers and STOPP criteria to detect adverse drug events, hospitalizations, and emergency department visits in the United States. J Am Geriatr Soc. 2016;64(1):22. doi:10.1111/ jgs. 13884

21. Meurer WJ, Potti TA, Kerber KA, et al. Potentially inappropriate medication utilization in the emergency department visits by older adults: analysis from a nationally representative sample. Acad Emerg Med. 2010;17(3):231-237. doi:10.1111/j.1553-2712.2010.00667.x

22. Chang C-B, Lai H-Y, Hwang S-J, et al. Prescription of potentially inappropriate medication to older patients presenting to the emergency department: a nationally representative population study. Sci Rep. 2018;8(1):1-8. doi:10.1038/s41598-018-30184-4

23. Hustey FM, Wallis N, Miller J. Inappropriate prescribing in an older ED population. Am J Emerg Med. 2007;25(7):804-807. doi:10.1016/ j.ajem.2007.01.018

24. Harrison L, O’Connor E, Jie C, Benzoni T, Renner CH, McCracken R. Potentially inappropriate medication prescribing in the elderly: is the beers criteria relevant in the emergency department today? Am J Emerg Med. 2019;37(9):1734-1737. doi:10.1016/j. ajem.2019.05.052

25. Al-Azayzih A, Alamoori R, Altawalbeh SM. Potentially inappropriate medications prescribing according to Beers criteria among elderly outpatients in Jordan: a cross sectional study. Pharm Pract (Granada). 2019;17(2):1439. doi:10.18549/PharmPract.2019.2.1439

26. Fabbri E, Zoli M, Gonzalez-Freire M, Salive ME, Studenski SA, Ferrucci L. Aging and multimorbidity: new tasks, priorities, and frontiers for integrated gerontological and clinical research. $J \mathrm{Am}$ Med Dir Assoc. 2015;16(8):640-647. doi:10.1016/j. jamda.2015.03.013

27. Toepfer S, Bolbrinker J, König M, Steinhagen-Thiessen E, Kreutz R, Demuth I. Potentially inappropriate medication in older participants of the Berlin aging study II (BASE-II)-Sex differences and associations with morbidity and medication use. PLoS One. 2019;14(12): e0226511. doi:10.1371/journal.pone.0226511

28. Rodriguez LAG, Cattaruzzi C, Troncon MG, Agostinis L. Risk of hospitalization for upper gastrointestinal tract bleeding associated with ketorolac, other nonsteroidal anti-inflammatory drugs, calcium antagonists, and other antihypertensive drugs. Arch Intern Med. 1998;158(1):33-39. doi:10.1001/archinte.158.1.33

29. Bajcar JM, Wang L, Moineddin R, Nie JX, Tracy CS, Upshur RE. From pharmaco-therapy to pharmaco-prevention: trends in prescribing to older adults in Ontario, Canada, 1997-2006. BMC Fam Pract. 2010;11(1):75. doi:10.1186/1471-2296-11-75

30. Liu YL, Chu LL, Su HC, et al. Impact of computer-based and pharmacist-assisted medication review initiated in the emergency department. $\quad J \quad$ Am Geriatr Soc. 2019;67(11):2298-2304. doi: $10.1111 /$ jgs. 16078

31. Moss JM, Bryan III WE, Wilkerson LM, et al. An interdisciplinary academic detailing approach to decrease inappropriate medication prescribing by physician residents for older veterans treated in the emergency department. J Pharm Pract. 2019;32(2):167-174. doi: $10.1177 / 0897190017747424$ 


\section{Publish your work in this journal}

Therapeutics and Clinical Risk Management is an international, peerreviewed journal of clinical therapeutics and risk management, focusing on concise rapid reporting of clinical studies in all therapeutic areas, outcomes, safety, and programs for the effective, safe, and sustained use of medicines. This journal is indexed on PubMed Central, CAS,
EMBase, Scopus and the Elsevier Bibliographic databases. The manuscript management system is completely online and includes a very quick and fair peer-review system, which is all easy to use. Visit http://www.dovepress.com/testimonials.php to read real quotes from published authors. 